Supporting Information for

\title{
Polydopamine Nanotubes as an effective fluorescent quencher for highly sensitive and selective detection of biomolecules assisted with Exonuclease III amplification
}

Daoqing Fan, ${ }^{\dagger}$ Xiaoqing Zhu, ${ }^{\dagger}$ Qingfeng Zhai, ${ }^{\dagger}$ Erkang Wang ${ }^{\dagger}$, Shaojun Dong $*{ }^{\dagger \dagger}$

${ }^{\dagger}$ State Key Laboratory of Electroanalytical Chemistry, Changchun Institute of Applied Chemistry, Chinese Academy of Sciences, Changchun, Jilin, 130022, China.

$\$$ University of Chinese Academy of Sciences, Beijing, 100039, China.

*Corresponding Author

E-mail: dongsj@ciac.ac.cn Fax:+86-43185689711 
Table S1. Sequences of DNA strands used in this work. The mismatched bases were italicized.

\begin{tabular}{cc}
\hline Name & Sequence ( $\mathbf{5}$ ' to $\mathbf{3}$ ' ) \\
\hline AMCA-FH & AMCA-AGAGATTTTCCACACTGACT \\
Cy5-FH & Cy5-AGAGATTTTCCACACTGACT \\
TAMRA-FH & TAMRA-AGAGATTTTCCACACTGACT \\
FH-DNA & FAM-AGAGATTTTCCACACTGACT \\
HIV & AGTCAGTGTGGAAAATCTCTAGC \\
MS1 & AGTCAGTGTGGACAATCTCTAGC \\
MS3 & AGTGAGTCTGGACAATCTCTAGC \\
Random & TTTTTTTTTTTTTTTTTTTTTT \\
ABA & FAM-ACCTGGGGGAGTATTGCGGAGGAAGGT \\
\hline
\end{tabular}

Table S2. The parameters during fluorescent tests of four kinds of fluorophores.

\begin{tabular}{|c|c|c|c|c|}
\hline Fluorophores & $\begin{array}{c}\text { Excitation } \\
\text { Wavelength/nm }\end{array}$ & $\begin{array}{c}\text { Emission } \\
\text { Wavelength/nm }\end{array}$ & $\begin{array}{c}\text { Slit width } \\
\text { (ex/em) }\end{array}$ & $\begin{array}{c}\text { Spectra range } \\
\text { collected/nm }\end{array}$ \\
\hline AMCA & 355 & 448 & $10 / 20$ & $420-580$ \\
\hline FAM & 490 & 520 & $10 / 10$ & $505-650$ \\
\hline Cy5 & 625 & 660 & $10 / 20$ & $650-800$ \\
\hline TAMRA & 535 & 575 & $10 / 20$ & $560-700$ \\
\hline
\end{tabular}



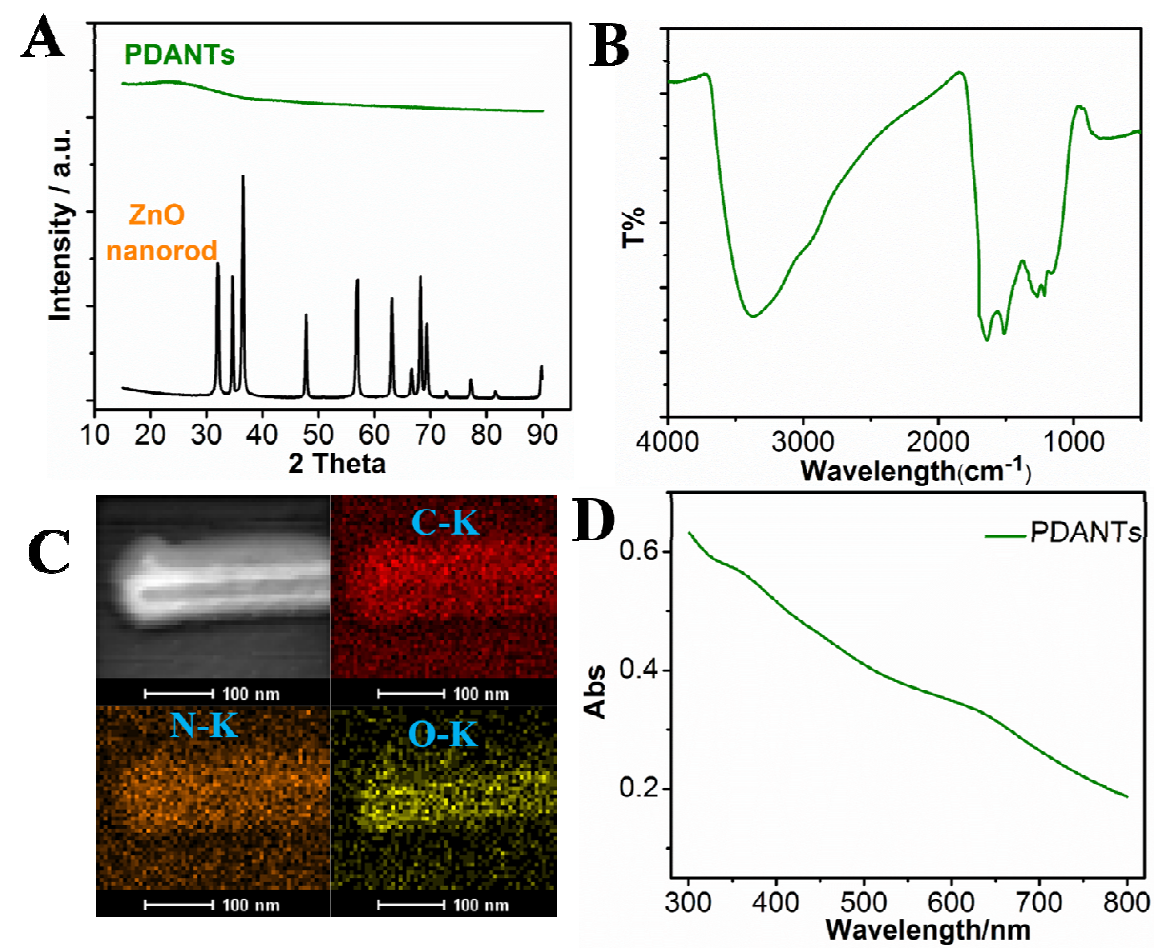

Figure S1. (A) XRD patterns of $\mathrm{ZnO}$ nanorod (black line) and PDANTs (green line); (B) FT-IR spectra of PDANTs; (C) Selected-area elemental analysis mapping images of C (red), N (orange) and $\mathrm{O}$ (yellow) of PDANTs; (D) Abs spectra of PDANTs.

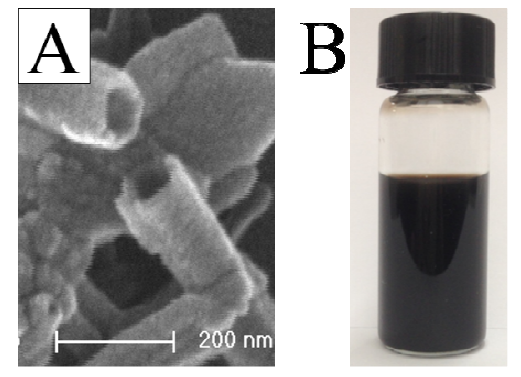

Figure S2. (A) SEM images of cross-section for as synthesized PDANTs under high resolution; (B) The photo of as obtained PDANTs dispersed in distilled water. 

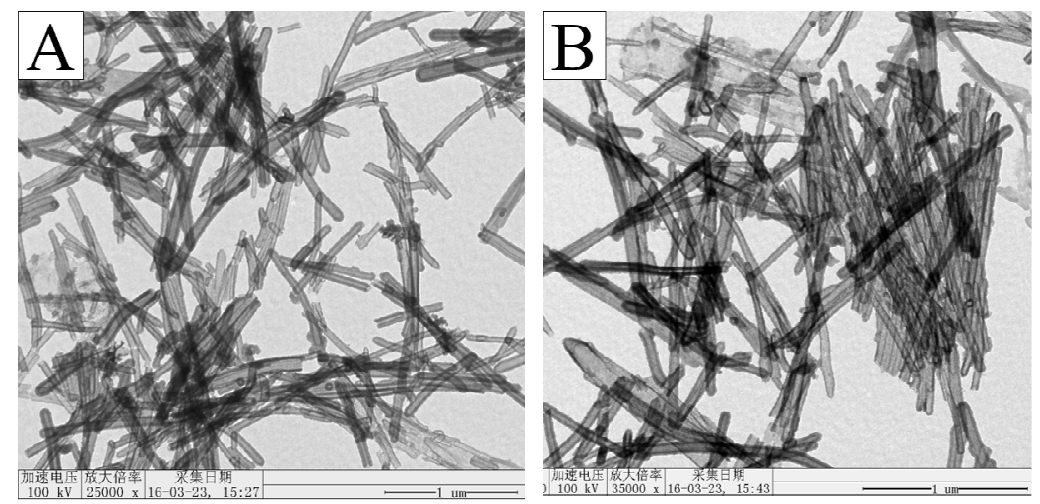

Figure S3. (A) TEM images of freshly prepared PDANTs and (B) that after stored at room temperature for about two months.
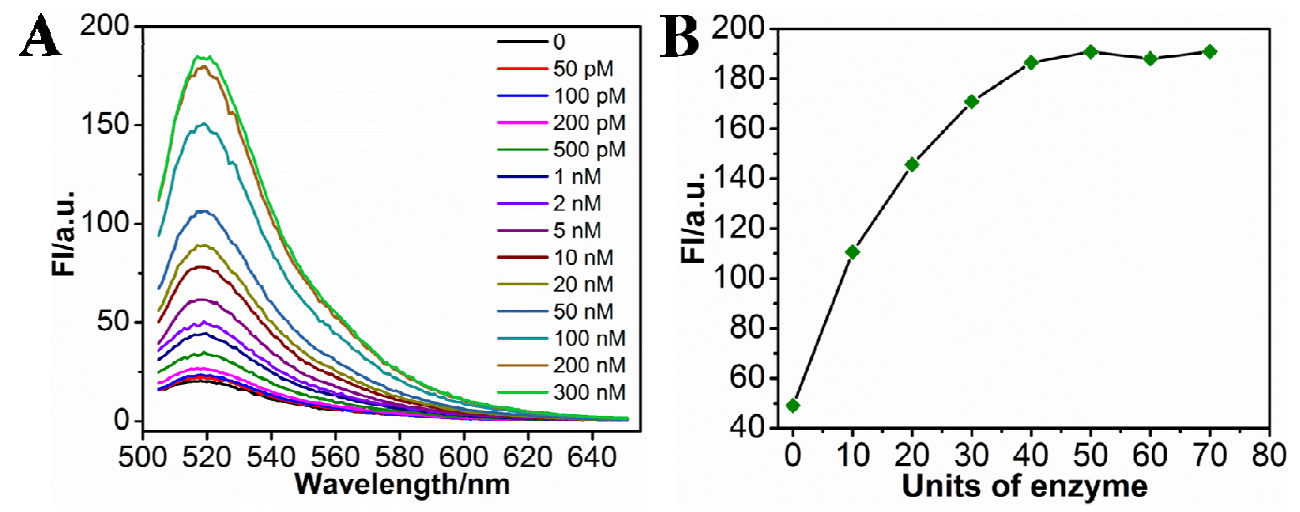

Figure S4. (A) Fluorescence spectra of $50 \mathrm{nM}$ FH DNA in the presence of PDANTs and different concentrations of HIV DNA without enzyme; (B) Optimization of units of Exo III used in this work. 


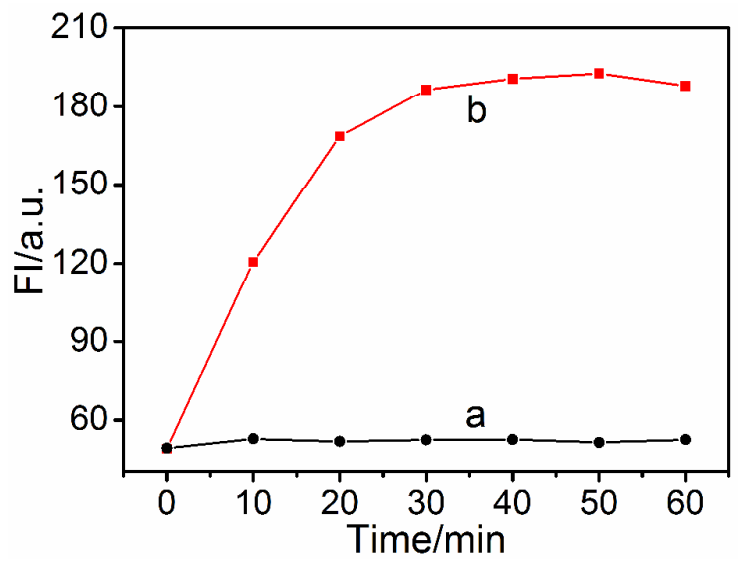

Figure S5. (a) Fluorescence intensities of $50 \mathrm{nM} \mathrm{FH} \mathrm{DNA}$ as a function of incubation time in the presence of solely Exo III; (b) Fluorescence intensities of $50 \mathrm{nM}$ FH DNA as a function of incubation time in the presence of $20 \mathrm{nM}$ target HIV DNA and Exo III.

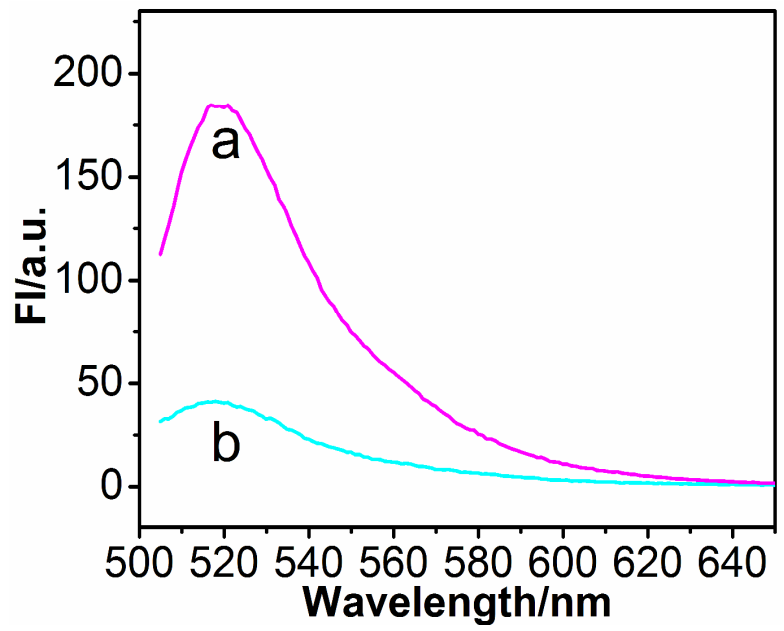

Figure S6. (a) Fluorescence spectra of $50 \mathrm{nM}$ FH DNA in the presence of $20 \mathrm{nM}$ target HIV DNA and PDANTs and Exo III; (b) Fluorescence spectra of $50 \mathrm{nM}$ FH DNA in the presence of $20 \mathrm{nM}$ Random DNA and PDANTs and Exo III. 

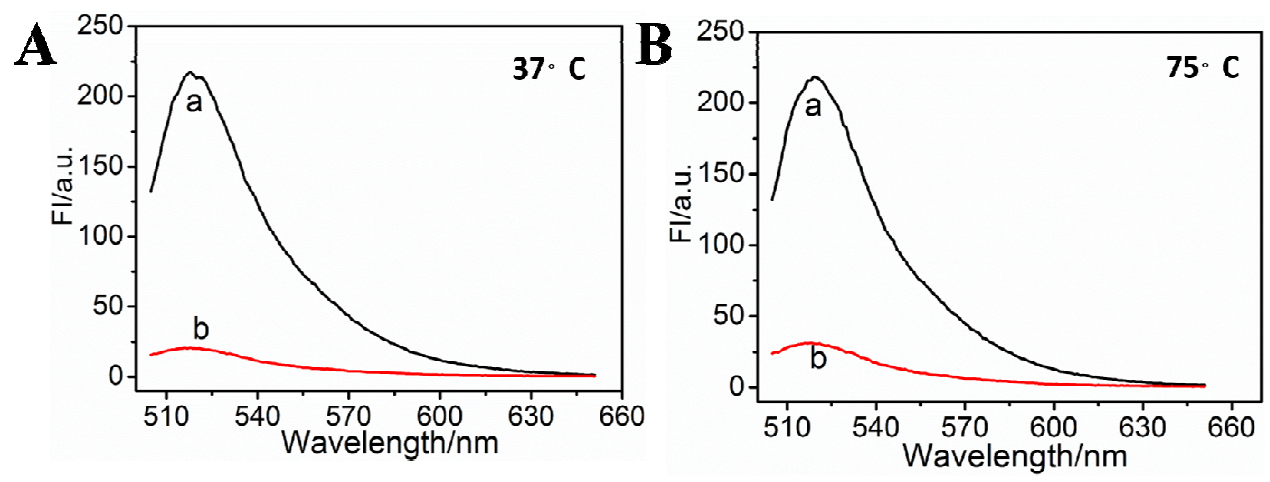

Figure S7. (A) Fluorescence spectra of $50 \mathrm{nM}$ FH DNA in the absence (a) and presence (b) of PDANTs at $37^{\circ} \mathrm{C}$; (B) Fluorescence spectra of $50 \mathrm{nM}$ FH DNA in the absence (a) and presence (b) of PDANTs at $75^{\circ} \mathrm{C}$.

As can be seen in Figure S7 A (a) and (B) (a), the fluorescence intensity of FH DNA at $37^{\circ} \mathrm{C}$ presented almost the same value with that at $75^{\circ} \mathrm{C}$, which indicated that the terminated temperature has nearly no effect on the fluorescence of free FH-DNA. Besides, the fluorescence intensity of FH DNA in the presence of PDANTs at $75^{\circ} \mathrm{C}$ (Figure S7 B (b)) is only little higher than that at $37^{\circ} \mathrm{C}$ (Figure $\mathbf{S} 7 \mathbf{A}(\mathbf{b})$ ), this phenomenon proved that the release of fluorescent dye from PDANTs will hardly occur at the terminated temperature $\left(75^{\circ} \mathrm{C}\right)$.
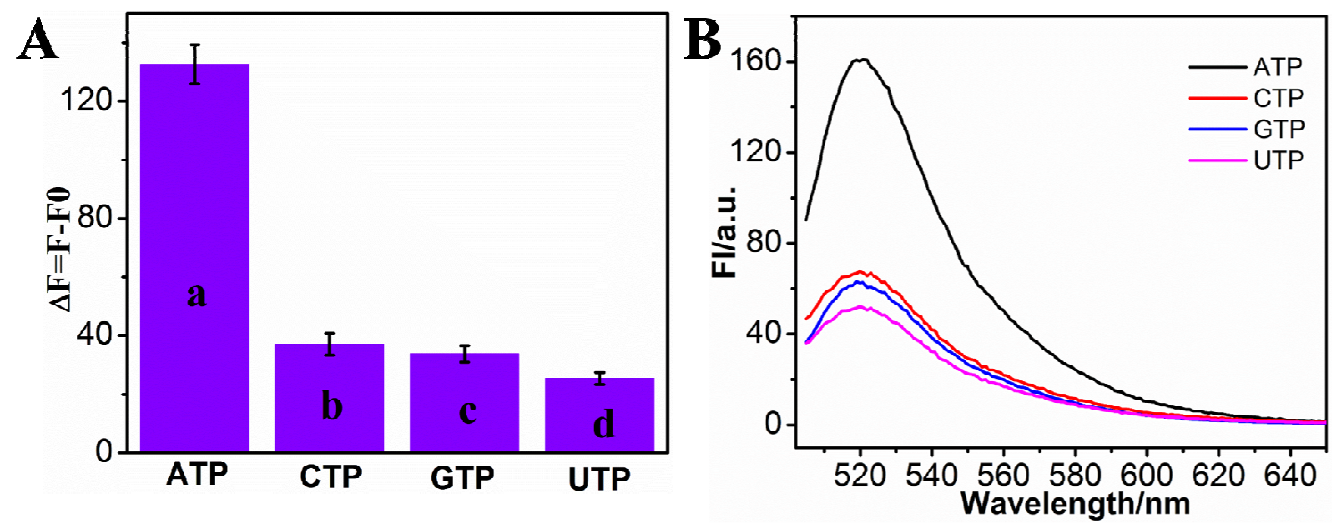

Figure S8. (A) Fluorescence intensity changes of ABA DNA in the presence of $200 \mu \mathrm{M}$ target ATP (a) and the same concentrations of CTP (b), GTP (c) and UTP (d); (B) Corresponding fluorescence spectra of Figure S8 (A). 

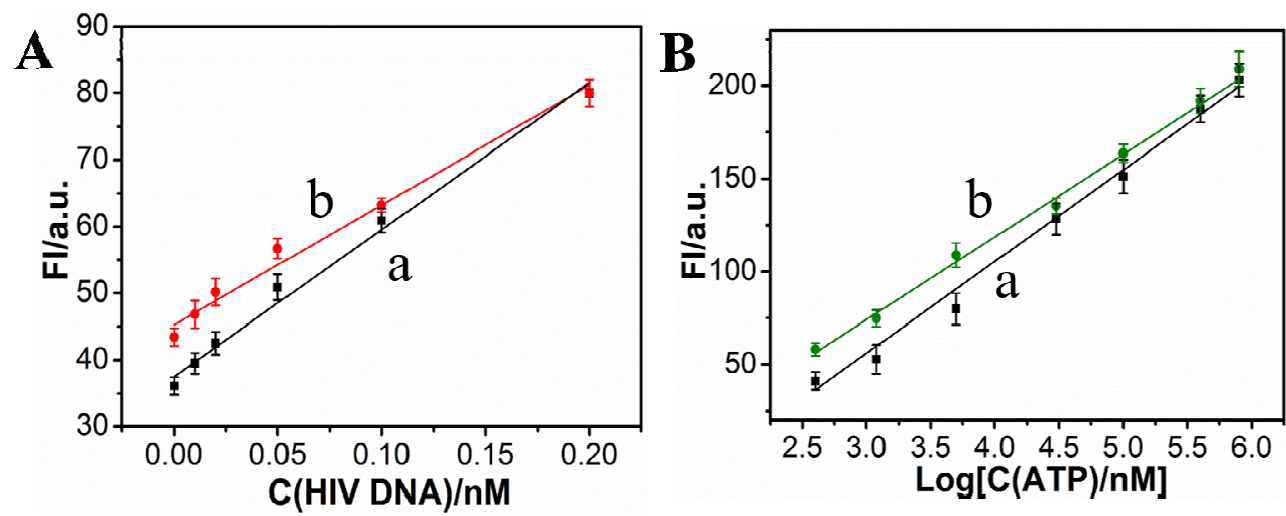

Figure S9. (A) The linear relationship between the fluorescence intensity at $520 \mathrm{~nm}$ and different concentrations of HIV DNA ranging from $10 \mathrm{pM}$ to $20 \mathrm{nM}$ in the presence of Exo III in Tris-HCl buffer (a, $\mathrm{R}^{2}=0.988$ ) and fifty times diluted fetal bovine serum $\left(\mathbf{b}, \mathrm{R}^{2}=0.979\right)$, respectively; (B) The linear relationship between the fluorescence intensity at $520 \mathrm{~nm}$ and logarithmic values of ATP's concentration ranging from $0.35 \mu \mathrm{M}$ to $800 \mu \mathrm{M}$ in the presence of Exo III in Tris-HCl buffer $\left(\mathbf{a}, \mathrm{R}^{2}=0.991\right)$ and fifty times diluted fetal bovine serum $\left(\mathbf{b}, \mathrm{R}^{2}=0.995\right)$, respectively. 